\title{
Surface Modification of PEEK and Its Osteoconductivity and Anti-Inflammatory Properties
}

\author{
Kensuke Kuroda $^{1 *}$, Kenta Igarashi², Hiroyasu Kanetaka ${ }^{3}$, Masazumi Okido ${ }^{1}$ \\ ${ }^{1}$ Institute of Materials and Systems for Sustainability, Nagoya University, Nagoya, Japan \\ ${ }^{2}$ Department of Materials Science and Engineering, Graduate School of Engineering, Nagoya University, Nagoya, Japan \\ ${ }^{3}$ Liaison Center for Innovative Dentistry, Graduate School of Dentistry, Tohoku University, Sendai, Japan \\ Email: ^kkuroda@numse.nagoya-u.ac.jp
}

How to cite this paper: Kuroda, K., Igarashi, K., Kanetaka, H. and Okido, M. (2018) Surface Modification of PEEK and Its Osteoconductivity and Anti-Inflammatory Properties. Journal of Biomaterials and Nanobiotechnology, 9, 233-243. https://doi.org/10.4236/jbnb.2018.93013

Received: April 8, 2018

Accepted: June 23, 2018

Published: June 26, 2018

Copyright $\odot 2018$ by authors and Scientific Research Publishing Inc. This work is licensed under the Creative Commons Attribution International License (CC BY 4.0).

http://creativecommons.org/licenses/by/4.0/

\begin{abstract}
Polyetheretherketone (PEEK) is known as one of the "super-engineering plastics" and is used as an intervertebral disk spacer in the body. PEEK has a hydrophobic surface (water contact angle $(\mathrm{WCA})>80^{\circ}$ ) and high chemical resistance, and it is thus difficult to perform any surface treatment, such as hydrophilization. In this study, we aimed to form a hydrophilic surface on PEEK without coating layers by using hydroprocessing (aqueous solution processing), and we examined the osteoconductivity and anti-inflammatory properties of surface-treated PEEK in vivo compared with Ti implants. The WCA value of PEEK reached $\sim 20^{\circ}$ using a combination of immersion in a solution of $>16.2$ $\mathrm{M} \mathrm{H}_{2} \mathrm{SO}_{4}$ and ultraviolet irradiation $(172 \mathrm{~nm})$. In in vivo testing, the hydrophilization of PEEK by surface modification without a coating layer improved the osteoconductivity and anti-inflammatory properties. The relationship between the bone-implant contact ratio and the WCA values of the surface-modified PEEK agreed well with that of the surface-treated Ti.
\end{abstract}

\section{Keywords}

Polyetheretherketone, Hydrophilization, Protein Adsorption, Osteoconductivity, Inflammatory

\section{Introduction}

Polymer materials are used in the orthopedic and dental fields as important biomaterials alongside metallic and ceramic materials. In general, when biomaterials are used in the body, it is known that the bioresponse depends on surface 
characteristics such as hydrophilicity [1] [2] [3] [4]. Our previous study using valve metals and their alloys showed that hydrophilic metallic surfaces have high osteoconductivity [5]. Many kinds of polymers have a high chemical stability as well as a hydrophobic surface. For example, polyetheretherketone (PEEK), which is used as an intervertebral disk spacer, has a hydrophobic surface (water contact angle (WCA) $>80^{\circ}$ ); however, based on our previous studies with metallic materials, this feature does not indicate that PEEK has high biocompatibility. Indeed, postoperative infection caused by a PEEK disc spacer has been reported and solutions to such potential bio-incompatibility have been proposed [6]. PEEK is known as one of the "super-engineering plastics" that have a high chemical resistance; consequently, a surface treatment, such as hydrophilization, is very difficult to apply in the same manner as for polytetrafluoroethylene (PTFE). Initially, hydrophobic PEEK was coated with hydroxyapatite (HAp), which was believed to be a bioactive substance [7], but the adhesion of HAp on PEEK was poor. It is believed that the root of this problem is that PEEK shows very stable hydrophobicity.

Plasma irradiation is commonly used for the hydrophilization of various polymer materials [8]. However, the nearly line-of-sight nature of plasma irradiation and the normally relatively inhomogeneous irradiation can produce surface unevenness, thereby limiting the usefulness of this technique because many implants have a complex shape. In this study, we aimed to form a hydrophilic surface on PEEK without coating layers by using hydroprocessing (aqueous solution processing), and we examined the osteoconductivity and anti-inflammatory properties of the surface-treated PEEK compared with the surface-treated Ti implants in vivo.

\section{Theory of Polymer Hydrophilization}

It is well known that the copolymer of polylactic acid-glycolic acid (PLGA) degrades in the body [9]. However, its degradability is not very fast and acceleration methods have been proposed [10]; for example, it was reported that the immersion of PLGA into alkaline aqueous solution was effective in accelerating the degradation. In our preliminary experiment, a PLGA sheet was immersed in several aqueous solutions, such as distilled water (DW), and $\sim 5 \mathrm{~mol} \mathrm{~L}^{-1} \mathrm{NaOH}$ aqueous solution ( $\mathrm{NaOHaq}$ ). Figure 1 shows the change in the WCA of the PLGA sheet with time. The immersion in DW decreased the WCA, but not at a fast rate and the WCA value converged to $\sim 80^{\circ}$, after which it remained unchanged. After immersion in $\mathrm{NaOHaq}$, the WCA decreased more quickly than in DW and converged to a smaller value. That is, the hydrophilization by hydrolysis made only very slow progress and a higher $\mathrm{NaOH}$ content decreased WCA more quickly; moreover, the WCA value that was reached was smaller. It is thought that the neutralization (acid-base) reaction removed the acid compound formed from the hydrolysis and this advanced the degradation of PLGA. From this experiment, we considered that at least a two-step reaction was necessary as a 


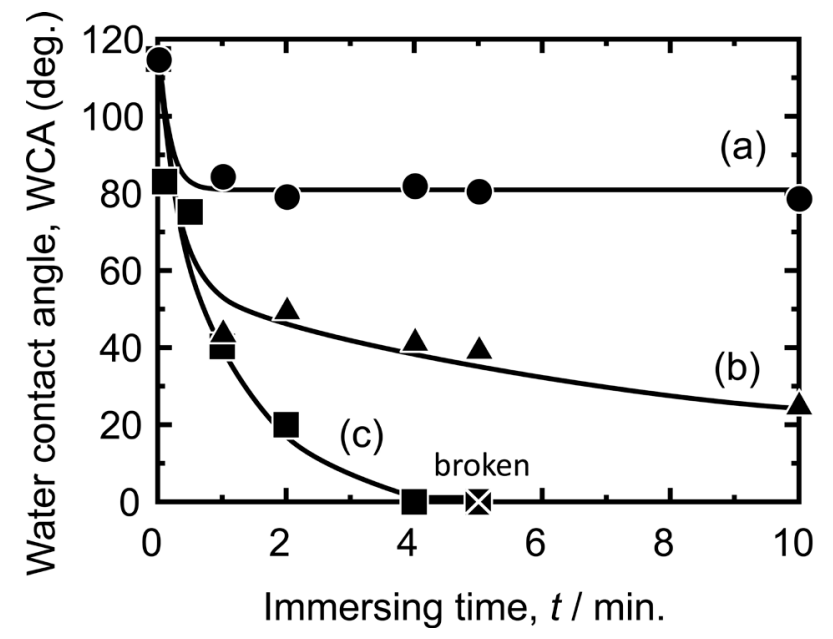

Figure 1. Water contact angle change with immersing time in (a) distilled water, (b) 0.1 $\mathrm{M} \mathrm{NaOH}$ aqueous solution, and (c) $0.5 \mathrm{M} \mathrm{NaOH}$ aqueous solution.

trigger for the hydrophilization of the polymer, disconnection of the bonds (e.g., hydrolysis), and its acceleration. In addition, fixation of the hydrophilic group (e.g., $-\mathrm{OH},-\mathrm{COOH})$ to the disconnected bond was an indispensable condition for hydrophilization.

\section{Experimental}

\subsection{Surface Modification}

We previously reported that the surface roughness of implants affected osteoconductivity after implantation [11]. PEEK plates $(\phi 6 \mathrm{~mm})$ were polished by buffing using $\mathrm{Al}_{2} \mathrm{O}_{3}$ particles (particle size $=0.05 \mu \mathrm{m}$ ) and the surface roughness (Ra) was set as $\mathrm{Ra} / \mu \mathrm{m}<0.1$. Samples were immersed in $\sim 18 \mathrm{M}\left(=\mathrm{mol} \mathrm{L}^{-1}\right)$ $\mathrm{H}_{2} \mathrm{SO}_{4}, \sim 12 \mathrm{M} \mathrm{HCl}, \sim 13 \mathrm{M} \mathrm{HNO}_{3}, \sim 17 \mathrm{M} \mathrm{CH}_{3} \mathrm{COOH}$, or $\sim 30$ vol. $\% \mathrm{H}_{2} \mathrm{O}_{2}$ for up to $1 \mathrm{~d}$ at $30^{\circ} \mathrm{C}$ for the disconnection of the ether bond in PEEK, considering the chemical resistance of PEEK. The immersed samples were picked up from the solution and rinsed in distilled water, acetone, ethanol, or toluene, respectively, and dried in vacuum. After drying, the samples were subjected to the following second step for the hydrophilization. The samples were irradiated either with ultraviolet (UV, 172, 254, or $365 \mathrm{~nm}$ wavelength) radiation for up to $6 \mathrm{~h}$ at $20^{\circ} \mathrm{C}$, or with atmospheric plasma for up to $1 \mathrm{~h}$. As a storing environment for the hydrophilicity of surface-treated samples, DW, phosphate buffered saline (PBS) $(-)$, five times concentrated PBS $(-)(\times 5$ PBS $(-))$, and air were selected, respectively, and the hydrophilicity value of the samples was maintained. In addition, the WCA of the sample surface was controlled using the change in storing period and environment. WCA was measured using a $2-\mu \mathrm{L}$ droplet of distilled water. The modified surfaces were analyzed using scanning electron microscopy (SEM), X-ray diffraction (XRD), X-ray photoelectron spectroscopy (XPS), and Fourier transform infrared spectroscopy (FTIR) in attenuated total reflection (ATR) mode. 


\subsection{Protein Adsorption Testing}

In the protein adsorption testing, fibronectin and albumin were picked up as a protein that was either a cell-adhesive protein or not, respectively [12]. A fibronectin $\left(\sim 1.0 \mathrm{mg} \mathrm{mL}^{-1}\right)$ or albumin $\left(\sim 50 \mathrm{mg} \mathrm{mL}^{-1}\right)$ aqueous solution droplet (40 $\mu \mathrm{L}$ ) was put on the surface of the WCA-controlled PEEK samples, respectively, and these were kept at $37^{\circ} \mathrm{C}$ for up to $3 \mathrm{~d}$. Then, they were rinsed out with ultrasonic cleaning in the distilled water and dried naturally. The amount of adsorbed protein was determined using FTIR in attenuated total reflection (ATR) mode. The protein content was evaluated from the peptide binding $\left(1650 \mathrm{~cm}^{-1}\right)$ in the protein in the FTIR spectra. The content of the different three positions was measured for each samples using calibration curve, and the mean value was calculated.

\subsection{In Vivo Testing}

All the animal studies were conducted in the laboratory at HAMRI Co., Ltd., Japan, of the Association for Assessment and Accreditation of Laboratory Animal Care International (AAALAC).

1) Testing of osteoconductivity [13]

The sides of PEEK rods ( $2 \mathrm{~mm}$ in diameter, $5 \mathrm{~mm}$ in length) were polished by buffing using $0.05 \mu \mathrm{m} \mathrm{Al} \mathrm{O}_{3}$ particles. Hydrophilic PEEK rods $\left(\mathrm{WCA}=85^{\circ}\right.$ ) were prepared in a combination of immersion in $16.2 \mathrm{M} \mathrm{H}_{2} \mathrm{SO}_{4}$ for $5 \mathrm{~s}$ at $30^{\circ} \mathrm{C}$ and UV irradiation $(172 \mathrm{~nm})$ for $3 \mathrm{~h}$. For the formation of the protein-adsorbed samples, hydrophilic PEEK samples were immersed in $1.0 \mathrm{mg} \mathrm{mL} \mathrm{m}^{-1}$ fibronectin aqueous solution for $48 \mathrm{~h}$ at $37^{\circ} \mathrm{C}$. Next, they were rinsed with ultrasonic cleaning in the distilled water and dried naturally. All the surface-treated rod samples $(n=5)$ before and after protein adsorption were implanted in rat tibia for $14 \mathrm{~d}$ for evaluation of osteoconductivity. The samples were longitudinally sliced and stained with toluidine blue. The interface between the implant and the cortical bone, as well as the cancerous bone, was observed by optical microscopy. The sum of the linear bone contact with the implant surface was measured and was expressed as a percentage over the entire implant length (the bone-implant contact ratio, BIC) in the cancerous bone and in the cortical bone parts. Significant differences in BIC were analyzed statistically using the Tukey-Kramer method [14].

\section{2) Testing of anti-inflammatory properties}

PEEK rods of $1 \mathrm{~mm}$ in diameter and $5 \mathrm{~mm}$ in length were used in the anti-inflammatory testing. The method of WCA control and fibronectin adsorption was the same as in the osteoconductivity testing. The surface-treated samples $(n=3)$ were implanted in the subcutaneous of the back of rats by inoculation using an injection needle and the rats were sacrificed at $14 \mathrm{~d}$ post implantation. Because serious inflammation, necrosis, suppuration, and bleeding were not detected around the surrounding tissue of implants by visual observation, tissue samples were fixed in $10 \%$ formalin, and embedded in methyl methacry- 
late (MMA) polymer. The samples were sliced and stained with toluidine blue. Optical microscope observation of the interface between the implanted and the surrounding tissue revealed whether inflammatory cells such as lymphocytes and neutrophils were present, as well as a new generation of vascular, and formation of a fibrous capsule film. The capsule film thickness of the eight positions was measured for each samples, and the mean value was expressed as an index of anti-inflammatory properties.

\section{Results and Discussion}

\subsection{Surface Modification}

Figure 2 shows photographs taken after immersion in several aqueous solutions and washing in distilled water. The immersion in $12 \mathrm{M} \mathrm{HCl}, 13 \mathrm{M} \mathrm{HNO}_{3}, 17 \mathrm{M}$ $\mathrm{CH}_{3} \mathrm{COOH}$, and 30 vol. $\% \mathrm{H}_{2} \mathrm{O}_{2}$ did not change the surface morphology of PEEK. The WCA values were $81^{\circ}, 84^{\circ}, 80^{\circ}$, and $83^{\circ}$, respectively, and they did not increase or decrease dramatically from the as-polished PEEK $\left(\sim 85^{\circ}\right)$. Immersion in $\mathrm{H}_{2} \mathrm{SO}_{4}$ had a clear effect on the surface appearance. In particular, $18 \mathrm{M} \mathrm{H}_{2} \mathrm{SO}_{4}$ attacked the surface and the color turned white from beige, and the Ra value increased from 0.05 to $0.44 \mu \mathrm{m}$. For immersion in $16.8 \mathrm{M} \mathrm{H}_{2} \mathrm{SO}_{4}$, SEM observation confirmed the attack, although discoloration and Ra change did not occur. For the immersion in less than $15 \mathrm{M}$, no changes were observed. Figure 3 shows FTIR spectra of samples after $18 \mathrm{M} \mathrm{H}_{2} \mathrm{SO}_{4}$ immersion (Figure 3(b)) and washing in DW (Figure $3(\mathrm{c})$ ). Figure 3 indicates that the immersion in $\mathrm{H}_{2} \mathrm{SO}_{4}$ broke the
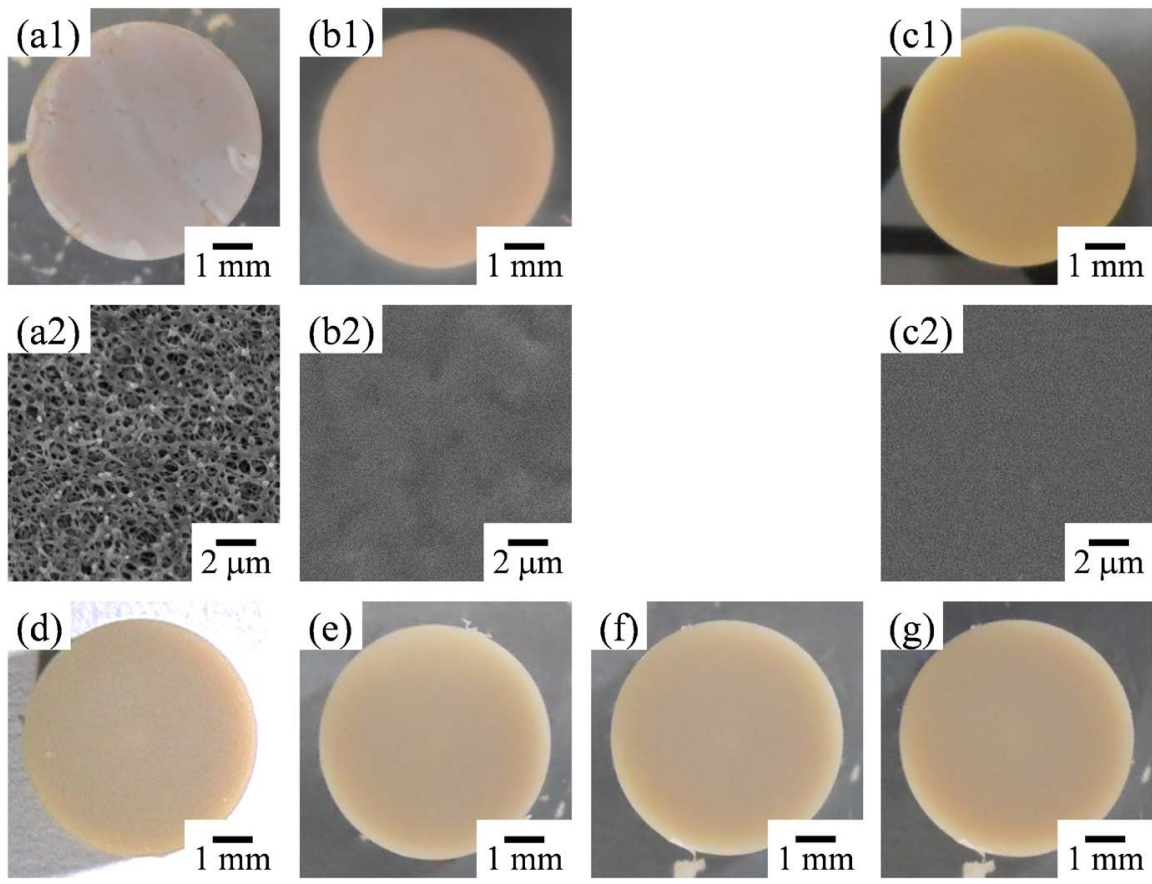

Figure 2. Optical micrograph and surface morphology of PEEK samples processed by immersion in different aqueous solutions: ((a1), (a2)) $18 \mathrm{M} \mathrm{H}_{2} \mathrm{SO}_{4}$, ((b1), (b2)) $16.2 \mathrm{M}$ $\mathrm{H}_{2} \mathrm{SO}_{4}$, ((c1), (c2)) as-polished, (d) $12 \mathrm{M} \mathrm{HCl}$, (e) $13 \mathrm{M} \mathrm{HNO}_{3}$, (f) $17 \mathrm{M} \mathrm{M} \mathrm{CH} \mathrm{COOH}_{3}$ and $(\mathrm{g}) 30$ vol. $\% \mathrm{H}_{2} \mathrm{O}_{2}$. 


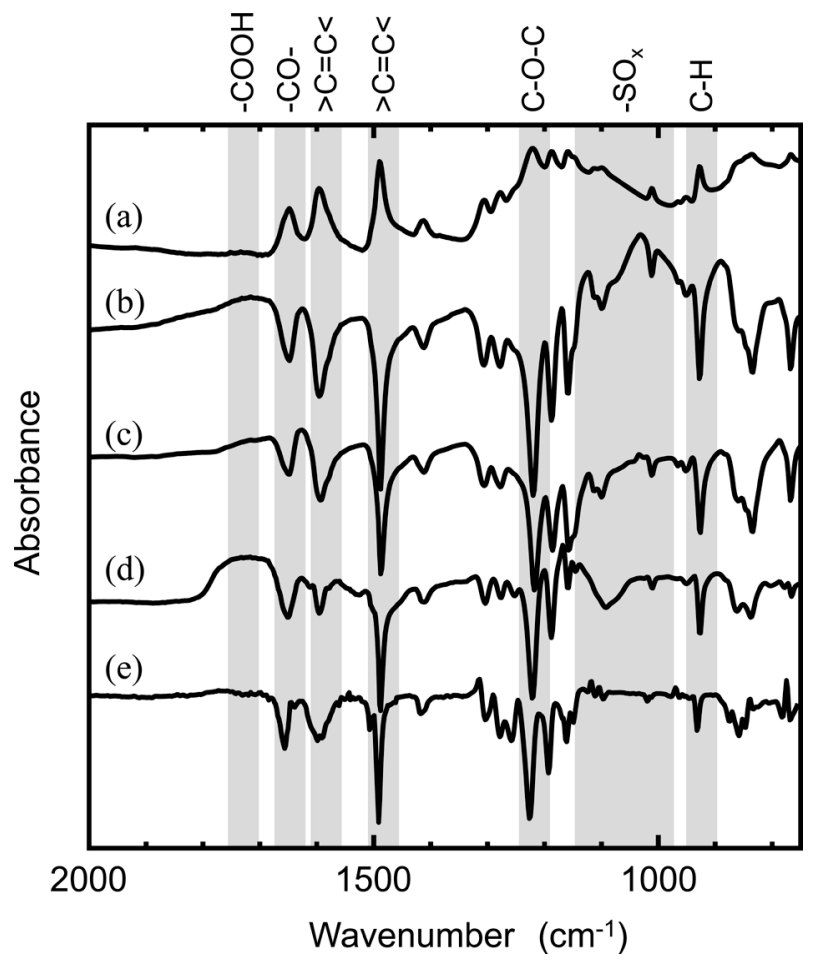

Figure 3. FT-IR spectra of PEEK samples processed by following treatment: (a) as-polished, (b) immersion in $18 \mathrm{M} \mathrm{H}_{2} \mathrm{SO}_{4}$, (c) after rinse of (b) in distilled water, (d) after ultraviolet (UV) irradiation (172 $\mathrm{nm}$ ) to (c), and (e) atmospheric plasma irradiation to (c).

ether bond, the $\mathrm{C}-\mathrm{C}$ single bond, and the $\mathrm{C}=\mathrm{C}$ double bond, and increased the sulfo group. Because the subsequent washing process decreased the sulfo group, it was thought that the WCA value did not decrease after immersion in $\mathrm{H}_{2} \mathrm{SO}_{4}$, which in any case satisfied the first step for polymer hydrophilization, that is, the disconnection of the bonds.

As a second step, UV $(172 \mathrm{~nm})$ irradiation $\left(>10 \mathrm{~mW} \mathrm{~cm}^{-2}\right.$, with $3 \mathrm{~mm}$ distance) and atmospheric plasma irradiation ( $500 \mathrm{~W}, 50 \mathrm{~mm}$ distance) were selected and applied on the solution-treated samples: immersion in $16.2 \mathrm{M} \mathrm{H}_{2} \mathrm{SO}_{4}$ for $5 \mathrm{~s}$ and rinsing in DW. With atmospheric plasma, the WCA value decreased rapidly and reached a constant WCA of $\sim 10^{\circ}$ in $10 \mathrm{~min}$, regardless of the first step. FTIR showed that there was no change in the surface functional group by the plasma treatment (Figure 3(e)), and therefore it was thought that radicals might contribute to hydrophilization. However, the hydrophilicity formed by plasma irradiation, could not be maintained, and the WCA value rose rapidly in $1 \mathrm{~d}$ (Figure 4). In contrast, it took $1-2 \mathrm{~h}$ for the solution-treated samples to reach a constant WCA of $\sim 20^{\circ}$ under UV irradiation, and the Ra value was the same as after $\mathrm{H}_{2} \mathrm{SO}_{4}$ immersion $(\mathrm{Ra}=0.05 \mu \mathrm{m})$. FTIR showed that the UV irradiation created a carboxyl group. By examination of UV irradiation under different partial pressure environments of $\mathrm{CO}_{2}$ ( $\mathrm{Ar}$ or $\mathrm{CO}_{2}$ atmosphere), we determined that this carboxyl group was formed from $\mathrm{CO}_{2}$ in air. The UV treatment on the as-polished sample gave a surface with $\sim 40^{\circ}$ and a longer irradiation time did not result in further reduction in WCA. The hydrophilicity could be kept for 


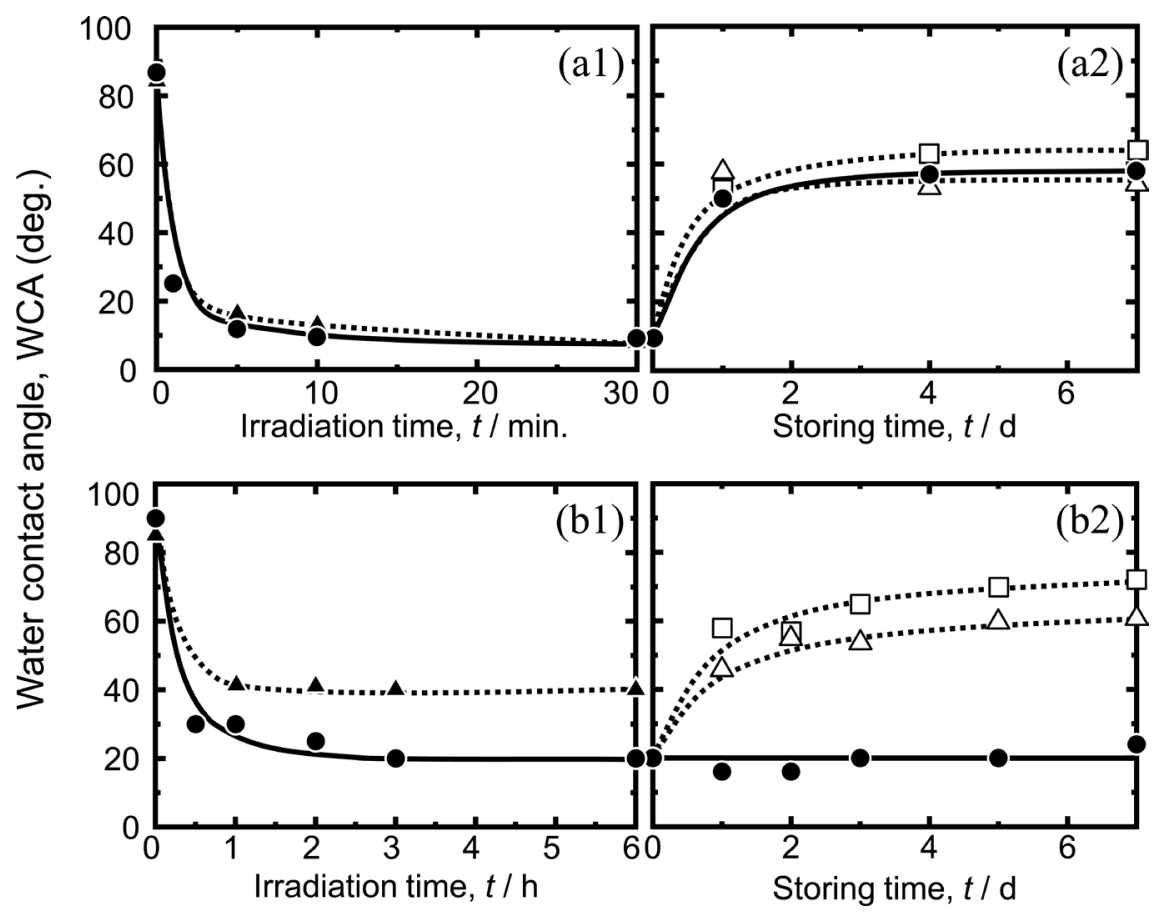

Figure 4. Water contact angle change with (1) irradiation time ( $\bullet: 18 \mathrm{M} \mathrm{H}_{2} \mathrm{SO}_{4}$ immersed sample and $\boldsymbol{\Delta}$ : as-polished sample) and (2) storing time ( $\bullet$ : five times concentrated phosphate buffered saline (x5 PBS(-)), $\square$ : air, and $\Delta$ : distilled water) of (a) atmospheric plasma irradiation and (b) ultraviolet (UV) irradiation $(172 \mathrm{~nm})$.

$7 \mathrm{~d}$ by storing in $\times 5$ PBS (-) in the same manner as hydrophilic Ti and its alloy samples [15]. It is thought that ions in $\times 5$ PBS $(-)$, such as $\mathrm{Na}^{+}$, were adsorbed on the hydrophilic PEEK surface. Thus, in the following hydrophilization experiment, PEEK was immersed in $16.2 \mathrm{M} \mathrm{H}_{2} \mathrm{SO}_{4}$ for $5 \mathrm{~s}$ and rinsed in $\mathrm{DW}$, and then irradiated with UV $(172 \mathrm{~nm})$ for more than $3 \mathrm{~h}$ in air. To maintain hydrophilicity, the surface-treated PEEK was stored in $\times 5$ PBS $(-)$.

\subsection{Evaluation of Osteoconductivity}

Figure 5 shows the relationship between the BIC value of surface-treated PEEK and WCA compared with WCA-controlled Ti. The BIC value of as-polished PEEK was very low, and a fibrous capsule film formed over the entire surface in some samples. In contrast, hydrophilic PEEK had a high BIC value. This tendency agreed well with our results for surface-treated $\mathrm{Ti}$ [15]. The hydrophilization of PEEK dramatically improved the osteoconductivity, meaning that the osteoconductivity strongly depended on the surface property and not on the implant materials themselves. Based on our previous work [16], we believed that the osteoconductivity was not directly affected by the WCA of the implants. In other words, it was thought that the WCA affected protein adsorption, which in turn controlled the osteoconductivity of the implants. The amount of adsorbed protein (fibronectin and albumin) with respect to the WCA value is shown in Figure 6(a) \& Figure 6(b). Neither protein was adsorbed on the as-polished PEEK surface. In contrast, on surface-treated PEEK, the proteins were adsorbed, 


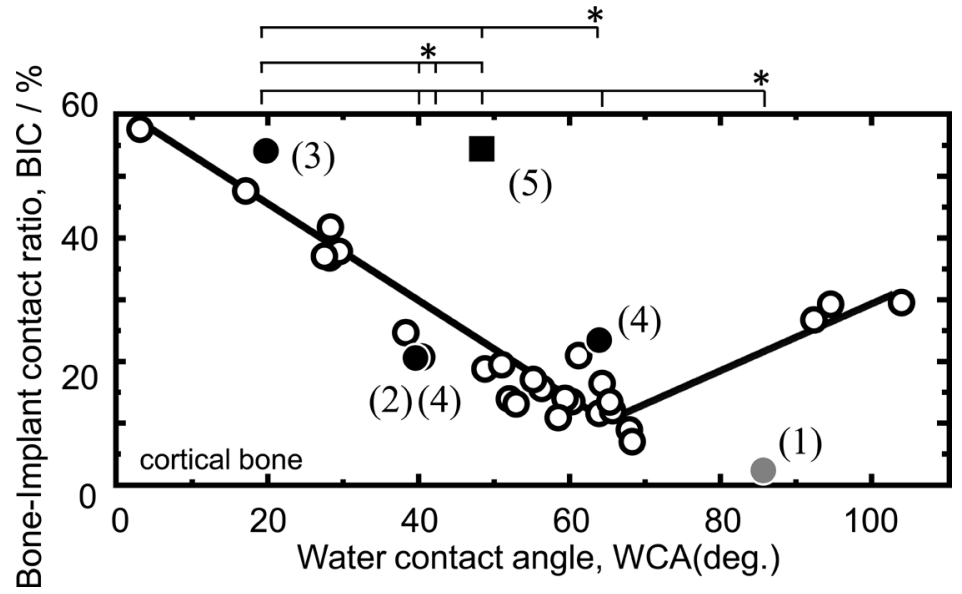

Figure 5. Relationship between bone-implant contact ratio (BIC) and water contact angle (WCA). (1) as-polished, (2) ultraviolet (UV) irradiated to as-polished, ((3), (4)) ultraviolet (UV) irradiated to $16.2 \mathrm{M} \mathrm{H}_{2} \mathrm{SO}_{4}$ immersed, and (5) fibronectin adsorbed to sample (3) and $\circ$ : surface treated Ti sample. ${ }^{*}: p<0.05$.

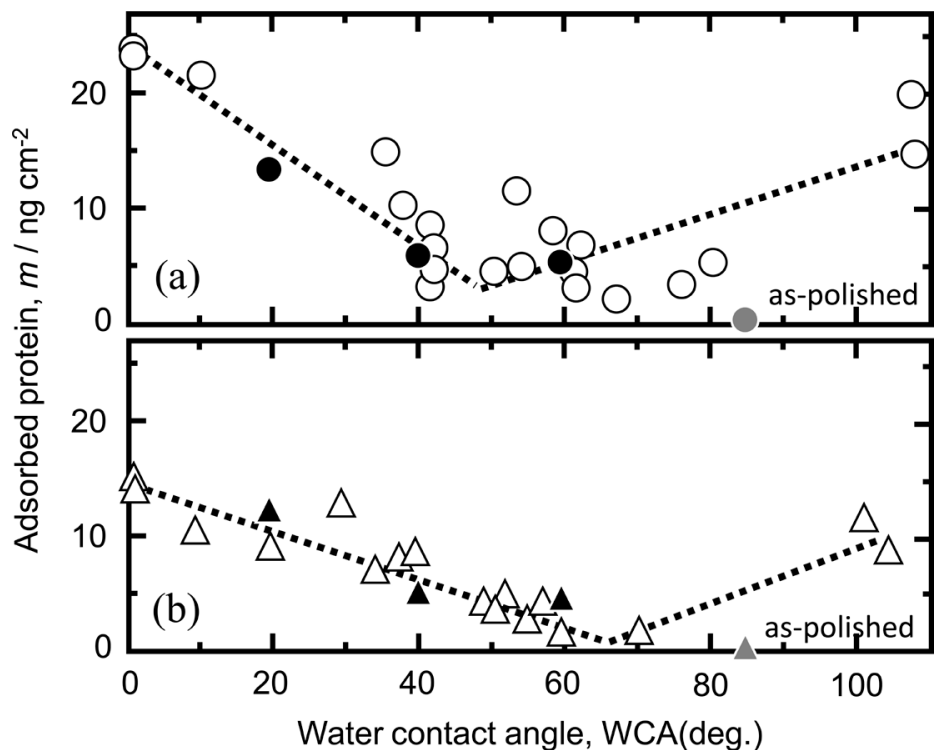

Figure 6. Adsorbed value of protein ((a) fibronectin and (b) albumin) to the water contact angle controlled PEEK. $\bullet$ : fibronectin, $\boldsymbol{\Delta}$ : albumin, and $\circ, \Delta$ : surface treated Ti sample.

depending on the WCA value. This tendency agreed well with our results for surface-treated Ti [15]. The BIC value of the fibronectin-adsorbed samples ( $n=$ $5)$ on the hydrophilic samples $(n=3)$ was also high, and the same level of hydrophilic sample, in spite that the fibronectin-adsorbed sample did not have a hydrophilic surface $\left(\mathrm{WCA}=48^{\circ}\right)$. This also supports the notion that the osteoconductivity was not directly affected by the WCA of implants.

\subsection{Evaluation of Anti-Inflammatory Properties}

Figure 7 shows photographs inside of the stripped skin and optical micrographs of surface-treated PEEK samples. Serious inflammation and necrosis were not 
detected around the surrounding tissue of implants. A fibrous capsule film formed over the entire surface in all samples, and the inflammatory reaction occurred over the whole surface of all samples. The thickness of the capsule film was used as an index for the evaluation of anti-inflammatory properties. Figure 8 shows the thickness of the capsule film formed on the implants. On the

(a1)

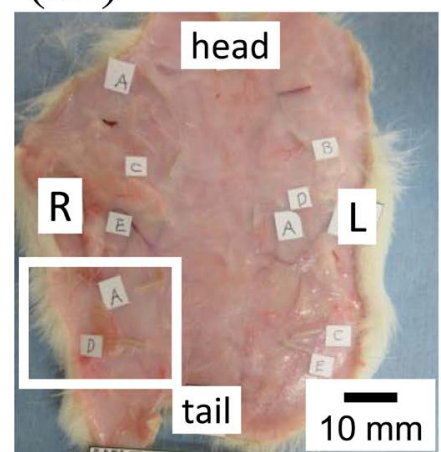

(a2)

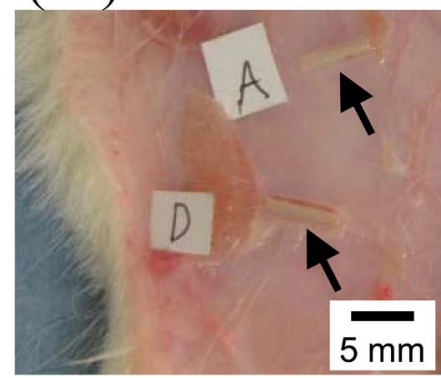

(b1)

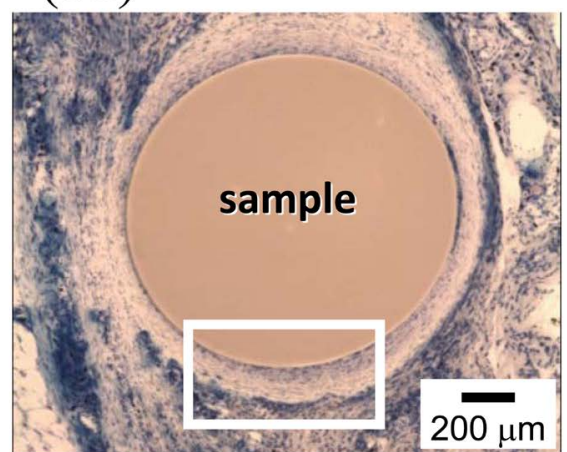

(b2)

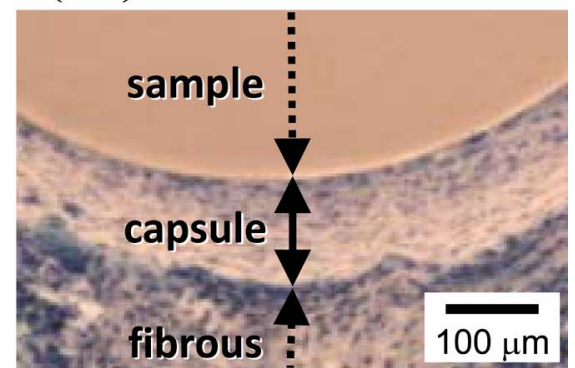

Figure 7. Photographs of the inside of the striped skin and the optical micrographs of surface treated PEEK samples implanted in the subcutaneous of back of rats for $14 \mathrm{~d}$.

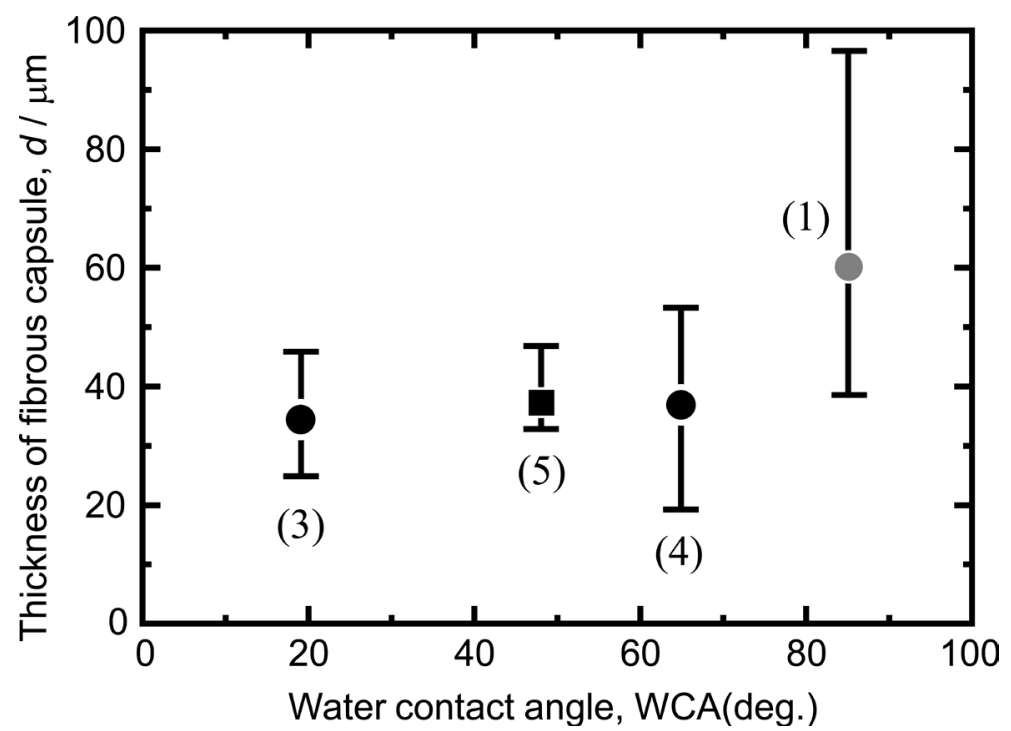

Figure 8. Relationship between the thickness of fibrous capsule and WCA. (1) as-polished, ((3), (4)) ultraviolet (UV) irradiated to $16.2 \mathrm{M} \mathrm{H}_{2} \mathrm{SO}_{4}$ immersed, and (5) fibronectin adsorbed to sample (3). 
as-polished sample, a thick capsule film was formed, suggesting that the inflammation was strong, as reported [17]. However, the inflammation was weaker on the surface-treated PEEK, which was not related to the WCA value. In the implantation of the fibronectin-adsorbed PEEK samples on the hydrophilic surface in advance, the inflammation was not suppressed further. It is noteworthy that the surface treatment can suppress the inflammation without an anti-inflammatory drug, compared with as-polished PEEK.

\section{Conclusion}

The WCA value of PEEK reached $\sim 20^{\circ}$ using a combination of immersion in $>16.2 \mathrm{M} \mathrm{H}_{2} \mathrm{SO}_{4}$ and $\mathrm{UV}$ irradiation (172 $\mathrm{nm}$ ). The immersion of the surface-treated PEEK in $\times 5$ PBS (-) maintained the hydrophilic WCA. Although as-polished PEEK could not adsorb protein, hydrophilization gave rise to protein adsorption. In vivo, the hydrophilization of PEEK by surface modification without a coating layer improved the osteoconductivity and anti-inflammatory properties. The relationship between BIC and WCA values of surface-modified PEEK agreed well with that of the surface-treated $\mathrm{Ti}$.

\section{Acknowledgements}

This research was financial supported partially by JSPS KAKENHI (Grant-in-Aid for Scientific Research (A) $15 \mathrm{H} 02310$ and (B) 25289248), and Joint Research Project on Life Innovation Materials by MEXT.

\section{Conflicts of Interest}

The authors declare that there are no conflicts of interest regarding the publication of this paper.

\section{References}

[1] Buser, D., Broggini, N., Wieland, M., Schenk, R.K., Denzer, A.J., Cochran, D.L., Hoffmann, B., Lussi, A. and Steinemann, S.G. (2004) Enhanced Bone Apposition to a Chemically Modified SLA Titanium Surface. Journal of Dental Research, 83, 529-533. https://doi.org/10.1177/154405910408300704

[2] Cochran, D.L., Buser, D., ten Bruggenkate, C.M., Weingart, D., Taylor, T.M., Bernald, J.P., Peters, F. and Simpson, J.P. (2002) The Use of Reduced Healing Times on ITI $^{\circledast}$ Implants with a Sandblasted and Acid-Etched (SLA) Surface: Early Results from Clinical Trials on ITI ${ }^{\circledR}$ SLA Implants. Clinical Oral Implants Research, 13, 144-153. https://doi.org/10.1034/j.1600-0501.2002.130204.x

[3] Eriksson, C., Nygren, H. and Ohlson, K. (2004) Implantation of Hydrophilic and Hydrophobic Titanium Discs in Rat Tibia: Cellular Reactions on the Surfaces during the First 3 Weeks in Bone. Biomater, 25, 4759-4766.

https://doi.org/10.1016/j.biomaterials.2003.12.006

[4] Park, J.-W., Park, K.-B. and Suh, J.-Y. (2007) Effects of Calcium Ion Incorporation on Bone Healing of Ti6Al4V Alloy Implants in Rabbit Tibiae. Biomater, 28, 3306-3313. https://doi.org/10.1016/j.biomaterials.2007.04.007

[5] Zuldesmi, M., Waki, A., Kuroda, K. and Okido, M. (2013) High Osteoconductive 
Surface of Pure Titanium by Hydrothermal Treatment. Journal of Biomaterials and Nanobiotechnology, 4, 284-290. https://doi.org/10.4236/jbnb.2013.43036

[6] Toth, J.M., Wang, M., Estes, B.T., Scifert, J.L., Seim, H.B. and Turmer, A.S. (2006) Polyetheretherketone as a Biomaterial for Spinal Applications. Biomater, 27, 324-334. https://doi.org/10.1016/j.biomaterials.2005.07.011

[7] Suzuki, N., Umeda, T., Sumi, T., Horikoshi, S., Kuwahara, H., Toyama, T., Musha, Y. and Itatani, K. (2016) Rapid Formation of Hydroxyapatite Layer on Polyetheretherketone by Vacuum Ultraviolet Irradiation and Microwave Heating Techniques. Journal of the Ceramic Society of Japan, 124, 49-54. https://doi.org/10.2109/jcersj2.15209

[8] Chvatalova, L., Cermak, R., Mracek, A., Grulich, O., Vesel, A., Ponizil, P., Minarik, A., Cvelbar, U., Benicek, L. and Sajdl, P. (2012) The Effect of Plasma Treatment on Structure and Properties of Poly(1-butene) Surface. European Polymer Journal, 48, 866-874. https://doi.org/10.1016/j.eurpolymj.2012.02.007

[9] Caffesse, R.G., Nasjleti, C.E., Morrison, E.C. and Sanchez, R. (1994) Guided Tissue Regeneration: Comparison of Bioabsorbable and Non-Bioabsorbable Membranes. Histologic and Histometric Study in Dogs. Journal of Periodontology, 65, 583-591. https://doi.org/10.1902/jop.1994.65.6.583

[10] Tsuchiya, S., Ohmori, M., Hara, K., Fujio, M., Ikeno, M., Hibi, H. and Ueda, M. (2015) An Experimental Study on Guided Bone Regeneration Using a Polylactide-co-glycolide Membrane-Immobilized Conditioned Medium. The International Journal of Oral \& Maxillofacial Implants, 30, 1175-1186. https://doi.org/10.11607/jomi.3915

[11] Yamamoto, D., Kawai, I., Kuroda, K., Ichino, R., Okido, M. and Seki, A. (2011) Osteoconductivity of Anodized Titanium with Controlled Micron-Level Surface Roughness. Materials Transactions, 52, 1650-1654. https://doi.org/10.2320/matertrans.M2011049

[12] Porté-Durrieu, M.C., Guillemota, F., Pallu, S., Labrugère, C., Brouillaud, B., Bareille, R., Amédée, J., Barthe, N., Dard, M. and Baquey, Ch. (2004) Cyclo-(DfKRG) Peptide Grafting onto Ti-6Al-4V: Physical Characterization and Interest towards $\mathrm{Hu}$ man Osteoprogenitor Cells Adhesion. Biomater, 25, 4837-4846.

https://doi.org/10.1016/j.biomaterials.2003.11.037

[13] Kuroda, K., Nakamoto, S., Miyashita, Y., Ichino, R. and Okido, M. (2006) Osteoinductivity of HAp Films with Different Surface Morphology Coated by the Thermal Substrate Method in Aqueous Solutions. Materials Transactions, 47, 1391-1394. https://doi.org/10.2320/matertrans.47.1391

[14] Kramer, C.Y. (1956) Extension of Multiple Range Tests to Group Means with Unequal Numbers of Replications. Biometrics, 12, 307-310.

https://doi.org/10.2307/3001469

[15] Zuldesmi, M., Waki, A., Kuroda, K. and Okido, M. (2014) Enhancement of Valve Metal Osteoconductivity by One-Step Hydrothermal Treatment. Materials Science and Engineering: C, 42, 405-411. https://doi.org/10.1016/j.msec.2014.05.049

[16] Kuroda, K. and Okido, M. (2015) A New Approach for Controlling Osteoconductivity of Valve Metals Based on $\mathrm{TiO}_{2}$ Coatings on Ti Substrates. Materials Technology, 30, B13-B20. https://doi.org/10.1179/1753555714Y.0000000221

[17] Toth, J.M., Wang, M., Estes, B.T., Scifert, J.L., Seim III, H.B. and Turner, A.S. (2006) Polyetheretherketone as a Biomaterial for Spinal Applications. Biomater, 27, 324-334. https://doi.org/10.1016/j.biomaterials.2005.07.011 